\title{
Chemoenzymatic one-pot synthesis of chiral disubstituted 1,2,3-triazoles in aqueous media
}

\section{Camila de Souza de Oliveira, Álvaro Takeo Omori*}

Laboratório de Transformações IV, CCNH, Universidade Federal do ABC, Santo André-SP, Brazil

*alvaro.omori@ufabc.edu.br

Keywords: click chemistry, Bioreduction, one-pot synthesis

\section{INTRODUCTION}

The skeleton of substituted triazoles is present in many biologically active compounds, and most of them are commercially available for pharmaceutical purposes. Several methods for the preparation of this class of heterocycles are available.

In this work, we established a one-pot two step procedure, combining the 1,3-dipolar cycloaddition ${ }^{2}$ and an enantioselective reduction mediated by Daucus carota root (carrot) ${ }^{3}$.

\section{RESULTS AND DISCUSSION}

Firstly, meta and para azidoacetophenones were prepared in moderate yields by diazotation of corresponding aminoacetophenones followed by addition of sodium azide (scheme 1).

Scheme 1



Since the Hüisgen reaction (1,3-dipolar cycloaddition) and the bioreduction can be proceeded in water, we divided two approches for the synthesis of disubstituted triazoles. In the first, all the reagents were added in the same time. In this case, only the cycloaddition reaction were observed. Based on this result, we decided to reduce the acetophenone prior to the copper catalyzed reaction. (scheme 2).

Scheme 2

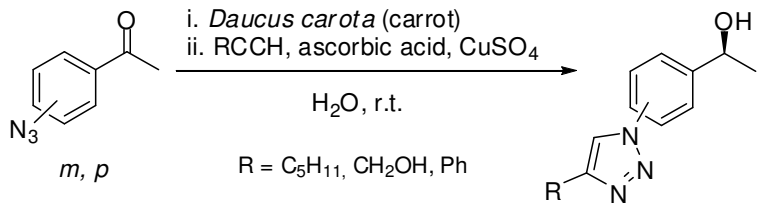

For evaluation of the method, we employed three different alkynes for each azidoacetophenone (1heptyne, phenylacetylene and propargyl alcohol) affording the chiral disubstituted triazoles (table 1).
Table 1. Synthesis of chiral disubstituted triazoles

\begin{tabular}{|c|c|c|}
\hline & $\begin{array}{c}\text { Reaction } \\
\text { time (days) }\end{array}$ & $\begin{array}{c}\text { Isolated } \\
\text { Yield (\%) }\end{array}$ \\
\hline
\end{tabular}

\section{CONCLUSION}

Although the moderate yields, we presented a useful method to the chemoenzymatic synthesis of chiral disubstituted triazoles using inexpensive, versatile and readily available reagents (water as solvent and carrot as biocatalyst).

\section{ACKNOWLEDGEMENTS}

FAPESP, CNPq, UFABC

\section{REFERENCES}

1. Melo, J. O. F.; Donnici, C. L.; Augusti, R.; Ferreira, V. F.; Souza, C. B.

V.; Ferreira, M. L. G. e Cunha, A. C. Quim. Nova, 2006, 29, 569.

2. Rostovtsev, V. V.; Green, L.G.; Fokin, V. V.; Sharpless, B. Angew. Chem. Int. 2002, 41, 2597.

3. Comasseto, J.V.; Omori, A.T.; Porto, A.L.M.; Andrade, L.H. Tetrahedron Lett. 2004, 45, 473. 